\title{
CONDIÇÕES SOCIOAMBIENTAIS URBANAS RELACIONADAS AS DOENÇAS TRANSMITIDAS PELO AEDES AEGYPTI (CULICIDAE - LINNAEUS, 1762) EM CUIABÁ, MT. BRASIL*
}

\author{
Rafaela Screnci-Ribeiro ${ }^{1}$
}

\section{INTRODUÇÃO}

O Aedes aegypti (Linnaeus, 1762) pertence à família Culicidae e é o responsável por transmitir doenças perigosas, como a dengue, zika e chikungunya. São insetos típicos de regiões urbanas onde predominam os climas tropical e subtropical. Os mosquitos dessa espécie apresentam pequeno tamanho, com média $0,5 \mathrm{~cm}$ de comprimento, coloração preta com manchas brancas no dorso, pernas e cabeça. As larvas apresentam coloração branca ao eclodir, mas tornam-se negras algumas horas depois (Natal, 2002).

O mosquito macho se alimenta de frutas e vegetais adocicados. Já a fêmea, alimenta-se de sangue animal, tendo predileção pelo sangue humano, e é nesse momento que ocorre a transmissão do vírus para o ser humano. Como esses mosquitos costumam voar a uma altura máxima de meio metro do solo, costumam picar o ser humano nos pés, tornozelos e pernas (Natal, 2002).

Esses indivíduos estão bem adaptados as zonas urbanas e no ano de 2016 foi descoberto que a fêmea não deposita os ovos apenas em água limpa e parada (Rodrigues, 2016). O mosquito pode se reproduzir também em águas com altos níveis de poluição (por exemplo: esgoto). Vários fatores são levados em consideração

1 Bióloga, Mestre em Ecologia e Conservação da Biodiversidade pela Universidade Federal de Mato Grosso e Doutora em Ecologia e Recursos Naturais pela Universidade Estadual do Norte Fluminense - Darcy Ribeiro. Professora substituta do Instituto de Biociências, Departamento de Botânica e Ecologia. Universidade Federal de Mato Grosso.78060.900. Cuiabá - MT rafita.ribeiro@gmail.com

* Trabalho de Conclusão de Curso de Pós-Graduação Lato sensu em Engenharia Ambiental e Saneamento Básico apresentado à Universidade Estácio de Sá. 
para que a fêmea decida o local da postura dos ovos, como a temperatura, a luminosidade e resquícios de matéria orgânica. Como as larvas são sensíveis à luz, elas se desenvolvem bem em águas turvas (Rodrigues, 2016). As zonas urbanas de países pobres ainda sofrem nos dias de hoje com deficiências de saneamento básico, habitação e de segurança pública.

Segundo Capurro (2015), o Aedes aegypti encontra-se em território brasileiro desde o início do século 20 e já era considerado um problema e na época foi erradicado com auxílio de inseticida químico. Em meados da década de 80, o mosquito já se alastrava novamente pelo território nacional, sendo reintroduzido através de espécies que vieram do continente asiático, principalmente de Cingapura (Braga e Valle, 2007). A erradicação através de inseticidas é improvável, uma vez que os mosquitos já se tornaram resistentes a eles (CAPURRO, 2015).

Essa nova disseminação de Aedes aegypti reflete às debilidades dos serviços de saúde e também as fragilidades das ações individuais para com a proteção da saúde coletiva (MENDONÇA, 2004). Segundo Mendonça et al. (2009), fatores como o rápido crescimento demográfico associado à intensa e desordenada urbanização, o aumento da produção de resíduos não-orgânicos, os modos de vida na cidade, a debilidade dos serviços e campanhas de saúde pública, bem como o despreparo dos agentes de saúde e da população para o controle da doença contribuíram para a proliferação dos mosquitos. E em contrapartida, o vetor desenvolve resistências cada vez mais evidentes às diversas formas de seu controle.

A primeira epidemia de dengue registrada no Brasil foi no Estado de Roraima em 1982, com aproximadamente 11 mil casos (UJAVARI, 2003). Anualmente ocorrem novas epidemias, principalmente durante o verão, época do ano que apresenta melhores condições climáticas de proliferação do Aedes aegypti. Na década de 1990, o número de casos teve um incremento considerável. Em 1995 foram registrados mais de 100 mil casos e a partir de 1997 foram registrados mais de 200 mil casos por ano. O ano de 2002 apresentou o maior número de casos notificados com 700 mil ocorrências (MENDONÇA et al., 2009). Em 2015 foram registrados 1,5 milhão de casos de dengue no país (SANTOS et al., 2016). 
De acordo com Junqueira et al. (2015) e a OMS (2000), a dengue é considerada um dos principais problemas de saúde pública do mundo, sendo registrada em cerca de cem países, com predominância de regiões de clima quente e baixo Índice de Desenvolvimento Humano (IDH).

Apesar do Brasil desenvolver ações de combate ao Aedes aegypti, sucessivamente são registradas epidemias de dengue e a partir de 2014, epidemias de Chikungunya e Zika passaram a ser registradas.

A Chikungunya foi introduzida no Brasil entre 2014 e 2015 por pessoas vindas da América Central e Venezuela, tendo encontrado no país ótimas condições para sua disseminação e se tornando mais um problema de saúde pública (JUNQUEIRA et al., 2015).

O Zika vírus foi isolado pela primeira vez em primatas não humanos em Uganda, em 1947. Entre 1951 e 2013, foram notificados casos da doença em humanos em diferentes países africanos. Em 2014, houve a primeira identificação do vírus no continente americano, na Ilha de Páscoa, no Chile. No Brasil, o primeiro caso confirmado de Zika vírus foi em 07 de maio de 2015 (Portal EBC, 2016).

Em Cuiabá, segundo dados divulgados pelo Centro de Informações Estratégicas de Vigilância em Saúde (CIEVS) da Prefeitura Municipal de Cuiabá, só em janeiro de 2017 já foram notificados 203 casos de dengue, 33 de Chikungunya e 53 de Zika, sendo 21 em gestantes (CIEVS, 2017).

Diante desta realidade, é de grande importância realizar uma análise da visão da população cuiabana frente ao Aedes aegypti, seu combate e as condições socioambientais urbanas relacionadas as doenças transmitidas por esse mosquito. E, por se tratar de um tema amplo, optou-se por uma análise da percepção humana frente a realidade que vivem, para entender suas ações, suas visões perante ao restante da sociedade e suas reflexões acerca das políticas públicas adotadas referentes às questões sanitárias.

\section{PROTOCOLO EXPERIMENTAL}

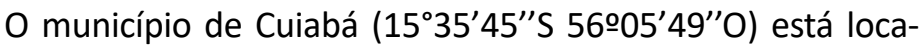
lizado na região Centro Sul do Estado de Mato Grosso, Brasil. O 
município apresenta área total de $3.538,167 \mathrm{~km}^{2}$ dos quais 126,9 $\mathrm{km}^{2}$ compõem a área urbana. A população atual estimada pelo Instituto Brasileiro de Geografia e Estatística é de 585.367 habitantes, apresentando densidade populacional de 165,44 habitantes $/ \mathrm{km}^{2}$ (IBGE, 2016).

De acordo com a classificação climática de Köppen, o clima da capital mato-grossense é classificado como tropical e úmido. As chuvas se concentram de outubro a abril, com precipitação média de 1300 milímetros anuais, sendo nos meses de janeiro, fevereiro e março as maiores intensidades. No resto do ano, entre maio e setembro, as massas de ar seco inibem as formações chuvosas. 0 calor associado à fumaça produzida pelas constantes queimadas nessa época seca, fazem com que a umidade relativa do ar apresente drástica redução, muitas vezes abaixo de $15 \%$. Nos meses mais quentes, a temperatura máxima pode chegar aos 40 ㄷ C e já nos meses mais frios, em média durante o mês de julho, a mínima média é de 16,6 .

A coleta de dados para essa pesquisa foi realizada no mês de janeiro de 2017, com 60 entrevistados. Foi realizada uma pesquisa descritiva quantitativa, ou seja, uma pesquisa que descreve características de certa população através de técnicas padronizadas de coletas de dados e generaliza os resultados da amostra para a população-alvo (CHAER et al., 2011).

Os dados foram coletados através de questionários estruturados e abrangeu moradores de diferentes localidades e realidades do município. Os participantes foram previamente informados do objetivo da pesquisa e ficaram livres para expor seus pensamentos e sua percepção relacionados a problemática abordada.

\section{RESULTADOS}

\section{Dados socioeconômicos}

$\mathrm{Na}$ totalidade foram entrevistadas 60 pessoas, sendo $55 \%$ mulheres e $45 \%$ homens. A faixa etária de 31 a 40 anos foi a que apresentou o maior número de participantes, representando $45 \%$ dos entrevistados (Figura 1). 


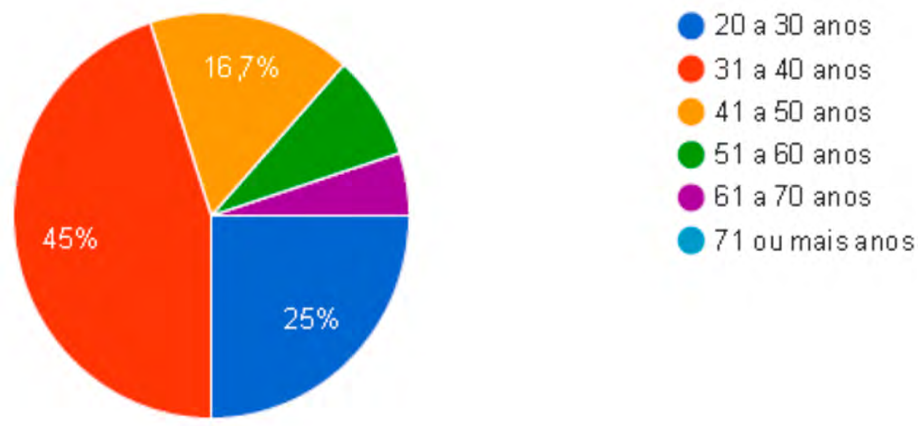

Figura 1. Distribuição dos entrevistados nas faixas etárias Cuiabá, MT. 2017.

Com relação ao grau de escolaridade, houve uma variação de Ensino Médio a Pós-Graduação (Figura 2). Em relação ao nível de escolaridade, notou-se que apenas 3,4\% dos entrevistados possuem Ensino Médio, enquanto 48,3\% dos entrevistados concluíram o ensino superior e os outros $48,3 \%$ possuem Pós-Graduação.
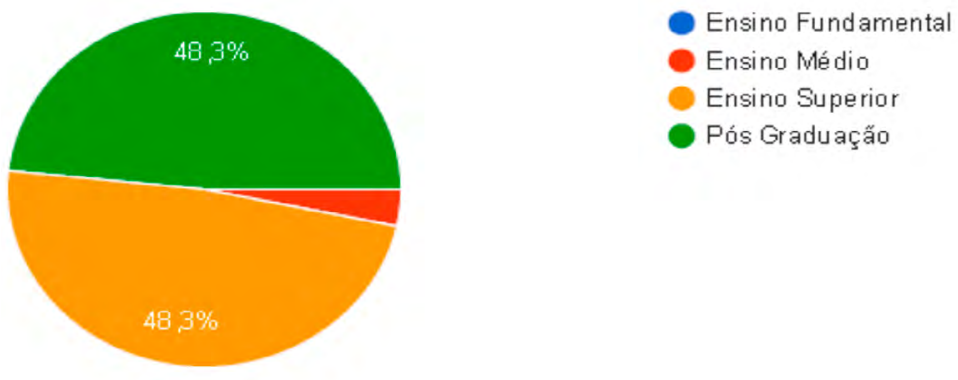

Figura 2. Grau de escolaridade dos entrevistados. Cuiabá, MT, 2017.

\section{Dados sanitários das residências dos entrevistados}

Entre os entrevistados, $80 \%$ afirmaram que o esgotamento sanitário das suas residências é realizado através de Estação de Tratamento de Esgoto e os demais 20\% afirmaram que é através de Fossa séptica. Quando questionados sobre a possibilidade de fossas sépticas propiciarem a procriação do mosquito, $88,1 \%$ afirmaram que quando a fossa se encontra aberta, a mesma contribui para a procriação. 
Com relação a coleta de lixo, 98,3\% dos entrevistados dispõem de coleta de lixo regular, em média ocorrendo 3 vezes na semana. Porém, 95\% dos mesmos afirma que existem falhas nessa coleta. Apenas $36,7 \%$ dos entrevistados possuem o hábito de separar lixo orgânico de lixo reciclável.

Com relação a água tratada e encanada, todos os entrevistados afirmaram dispor de seu acesso em sua residência.

\section{Percepção relacionada ao combate ao Aedes aegypti}

Do total dos entrevistados $98 \%$ afirmaram que o mosquito procria através da água parada e ainda afirmaram que a melhor maneira de evitar que o mosquito procrie é impossibilitando sua procriação evitando qualquer acúmulo de água.

A destinação adequada para o lixo é uma forma eficiente de combate ao Aedes aegypti, de acordo com 95\% dos entrevistados. Dos entrevistados, 98,3\% afirmam contribuir no combate a procriação do Aedes aegypti. Em contrapartida, 71,7\% dos entrevistados acreditam que a população em geral não contribui para esse combate.

Em relação as informações disponíveis e divulgadas relacionadas a forma de combate, $85,2 \%$ acreditam ser suficientes e de fácil acesso e entendimento para a população. $O$ trabalho da equipe de combate ao Aedes aegypti foi aprovado por $63,3 \%$ dos entrevistados e $98,3 \%$ acredita que o combate não deve ser realizado apenas pela Secretaria de Saúde.

O uso de inseticidas não foi considerado uma boa opção no combate ao Aedes aegypti por $55 \%$ dos entrevistados. A água de piscinas sem tratamento adequado com aplicação de cloro foi considerada uma ameaça por $95 \%$ dos entrevistados.

\section{Percepção ambiental relacionada ao Aedes aegypti}

Com relação ao mosquito Aedes aegypti, 88,3\% afirmam que os mosquitos fêmeas são os responsáveis por picar o ser humano. 73,3\% sabem identificar um mosquito de Aedes aegypti.

Relacionado a transmissão, 81,7\% afirmam que o mosquito deve estar infectado para transmitir a doença. 83,3\% responderam 
que o mosquito pica uma pessoa infectada e transmite para uma pessoa saudável (Figura 3).

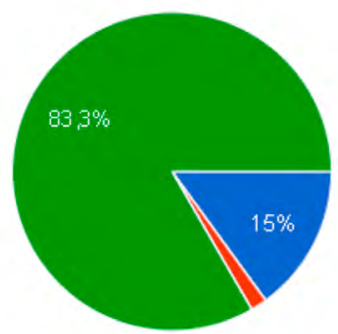

Água contaminada

Alimento contaminado

Uso de objetos pessoais do doente

O mosquito pica o doente e passa

para outra pessoa

Figura 3. Transmissão de doenças pelo Aedes aegypti para o ser humano. Cuiabá, MT, 2017.

Em relação ao tempo de vida do mosquito, $61,7 \%$ dos entrevistados não souberam responder e apenas $16,7 \%$ responderam corretamente, de 30 a 45 dias (Figura 4).
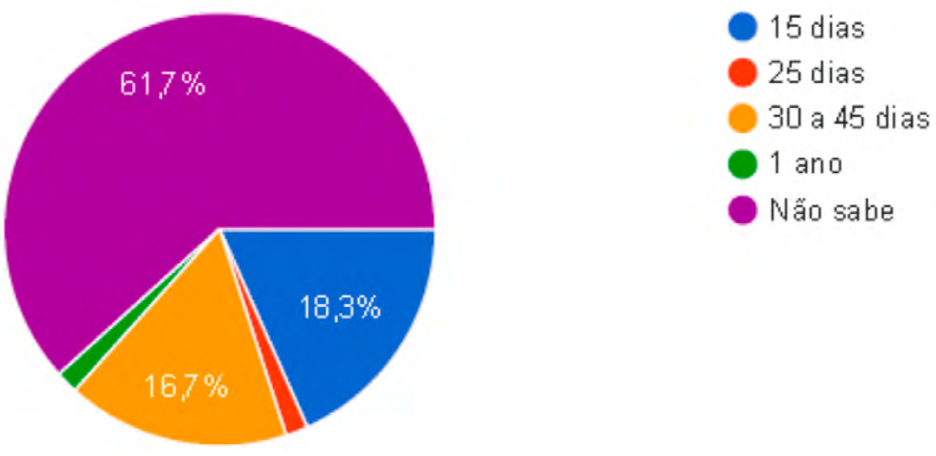

Figura 4. Ciclo de vida do mosquito Aedes aegypti. Cuiabá, MT, 2017.

Ao serem perguntados sobre quantas pessoas podem ser infectadas por um único mosquito durante seu ciclo de vida, apenas $6,7 \%$ das pessoas responderam corretamente, 200 pessoas (Figura 5). 

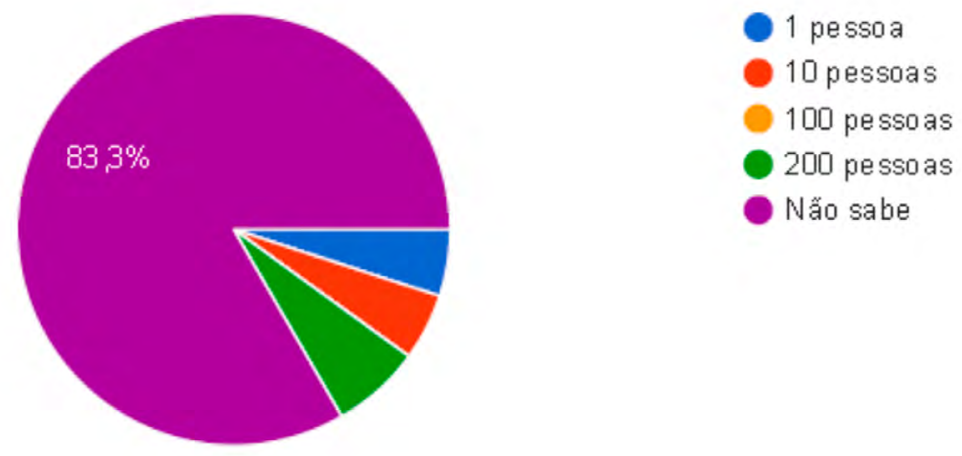

Figura 5. Número de pessoas que podem ser contaminadas por um único mosquito de Aedes aegypti. Cuiabá, MT, 2017.

Em relação ao tempo de sobrevivência de ovos ressecados $85 \%$ afirmaram que os ovos podem sobreviver até um ano sem contato com a água e, caso sejam molhados, podem eclodir. Quando perguntados se os sintomas da dengue podem ser confundidos com os de uma gripe forte, $86,7 \%$ dos entrevistados afirmaram que sim e por isso as pessoas demoram mais tempo para procurar atendimento médico.

A falta de conscientização e prevenção da população foi apontada por $98 \%$ dos entrevistados como principal responsável pelas ocorrências de doenças transmitidas pelo Aedes aegypti no município de Cuiabá, MT.

\section{DISCUSSÃO}

A maioria dos entrevistados nessa pesquisa é composta pela classe adulta jovem (31 a 40 anos) e possui instrução superior, sugerindo que detêm de conhecimento e acesso aos meios de informação e combate ao mosquito Aedes aegypti.

Mesmo os entrevistados afirmando que tomam as medidas de prevenção a proliferação do mosquito, os dados apresentados pelo CIEVS são alarmantes, uma vez que os casos de dengue, zika e chikungunya continuam sendo preocupantes para o município. Acredita-se que um dos grandes influenciadores da proliferação do mosquito, são os terrenos baldios sem cuidados, considerando que acumulam água e muitas pessoas aproveitam para descartar lixo 
e objetos que já não querem em suas residências, servindo como excelentes criadouros para o Aedes.

De acordo com Santos et al. (2016), o controle de infecções causadas por vírus transmitidos por mosquitos, principalmente no caso do Aedes aegypti, se dá através da redução, eliminação ou erradicação desse vetor. Cabe não só ao governo municipal viabilizar campanhas de conscientização e ações de combate, mas também a própria população tomar providências para esse controle.

Medidas simples como não jogar lixo nas ruas, não deixar vasos de plantas acumularem água, realizar manutenção adequada em piscinas, manutenção de terrenos baldios, não descartar objetos sem destinação adequada, entre outros, já contribuiriam para a redução de locais propícios para proliferação do vetor.

Zara et al. (2016) ressalta que o Brasil possui Agentes Comunitários de Saúde e Agentes de Combate a Endemias que devem atuar em parceria com a população, sendo responsáveis por promover o controle mecânico e químico do mosquito, através da detecção, destruição ou destinação adequada dos reservatórios naturais ou artificiais de água que servem de depósito para os ovos do vetor. Uma estratégia amplamente desenvolvida no município de Cuiabá pelo Centro de Zoonoses, é a de, através de agentes comunitários, promover frequentes visitas domiciliares com intuito de garantir a eliminação dos criadouros pelos proprietários das residências e demais imóveis e conscientizar as pessoas da importância das medidas preventivas na tentativa de reduzir a cadeia de transmissão das doenças causadas pelo Aedes.

Segundo Santos et al. (2016), melhorar as condições de saneamento reduziriam não só os criadouros potenciais do Aedes, mas também reduziriam outras doenças de transmissão hídrica. Cabe as esferas governamentais incorporarem novas práticas pedagógicas e de comunicação social em saúde que fortaleçam a consciência sanitária e ecológica e favoreçam mudanças de comportamento da população para reduzir a exposição ao vetor.

Historicamente falando, a Reforma Sanitária sofrida pelo Brasil teve como ponto de partida essa relação entre os mosquitos e a transmissão de doenças. O combate aos mosquitos fez com que se buscassem melhorias na qualidade de vida das populações através de condições de planejamento urbano, valorização do saneamento 
básico, higiene e saúde pública (MENDONÇA et al., 2009). Mesmo com todos esses esforços, não foi possível erradicar essas doenças transmissíveis com base no controle de vetores, tanto que houveram reincidências de doenças transmitidas pelo Aedes aegypti como a dengue e febre amarela e novas doenças, como é o caso de Zika e Chikungunya (MENDONÇA et al., 2009).

Observou-se que os entrevistados anseiam por melhorias nas questões sanitárias do município, mas compreendem que isso não é dever apenas do governo municipal. Reduzir ou dizimar os focos de criadouros de Aedes aegypti é dever de toda a população, pois através de pequenas ações e mudanças de atitude, essas metas poderiam ser alcançadas.

Seguindo o pensamento de Buss (2000), as políticas públicas saudáveis distinguem-se e ultrapassam as ações ambientais da saúde pública tradicional, as mesmas devem extrapolar a ideia de ausência de doença para também serem identificadas com bem-estar e qualidade de vida.

A cooperação de outros setores com o setor da saúde é fundamental para obter-se sucesso no combate aos vetores. De acordo com ZARA et al. (2016), macrofatores externos como saneamento básico, manejo adequado de resíduos sólidos e de lixo, abastecimento regular de água, educação em saúde, vigilância de fronteiras, turismo e intensa movimentação de pessoas são aspectos externos à saúde que precisam ser priorizados como alvos estratégicos de políticas sólidas, com o envolvimento de todos os setores da sociedade.

\section{REFLEXÕES FINAIS}

O processo saúde-doença da população vai muito além dos setores de saúde, fazem parte desse processo evolutivo questões sociais, culturais, políticas e econômicas. Todos esses fatores podem influenciar na expansão ou na redução de uma epidemia, além, claro, das questões climáticas, socioambientais e urbanas.

Conforme a observação realizada na presente pesquisa, notou-se que os entrevistados compreendem a importância de se praticar ações minimizadoras de possíveis focos de criadouros de Aedes aegypti. Os entrevistados ainda ressaltam que os serviços públicos 
de saneamento básico e coleta de lixo podem ser melhorados. Não existe coleta seletiva que atenda toda a cidade, o que faz com que as pessoas não adquiram o hábito de separar o lixo orgânico do lixo reciclável, o que poderia contribuir para a redução de material que poderia ser reciclado e é descartado erroneamente e se transforma em criadouro de Aedes aegypti.

Tendo em vista o que foi apresentado, sugerem-se maiores investimentos em metodologias que sensibilizem a população sobre a necessidade de mudança na postura frente ao controle do vetor; e manejo ambiental adequado que priorize e amplie ações de controle racional de vetores e assim garanta maior sustentabilidade as ações sem o uso de inseticidas que possam gerar um outro problema ambiental.

Foi possível concluir que os entrevistados sabem da sua responsabilidade perante as ocorrências de doenças transmitidas pelo Aedes aegypti e entendem que novas ações de combate em parceria com os órgãos municipais de saúde podem auxiliar na redução epidemias. Somente essa parceria irá possibilitar ao menos uma redução nos casos frequentes de epidemias de dengue que acompanhamos há anos e das epidemias mais recentes de Zika e Chikungunya.

As políticas públicas de saúde devem ser concebidas nos fundamentos que permeiam a qualidade de vida, principalmente, as condições sanitário-ambientais. Existe a necessidade de direcionar as práticas de educação permanente baseadas nas divergências educativas encontradas entre as populações. Compete ao Estado a promoção de diferentes suportes que permitam a busca pela saúde.

\section{REFERÊNCIAS}

BRAGA, I. A.; VALLE, D. Aedes aegypti: histórico do controle no Brasil. Epidemiol. Serv. Saúde, Brasília, v. 16, n. 2, p. 113-118, jun. 2007.

BUSS, P. M. Promoção da saúde e qualidade de vida. Ciência \& Saúde Coletiva, 5(1):163-177, 2000.

CAPURRO, N. Aedes aegypti: conheça a história do mosquito no Brasil e suas características. Disponível em http://agenciabrasil.ebc.com.br/geral/noticia/2015-12/aedes-aegypti-conheca-historia-do-mosquito-no-brasil-e-suas-caracteristicas 2015. 
CHAER, G.; DINIZ, R.R.P.; RIBEIRO, E.A. A técnica do questionário na pesquisa educacional. Evidência, Araxá, v. 7, n. 7, p. 251-266, 2011.

CENTRO DE INFORMAÇÕES ESTRATÉGICAS DE VIGILÂNCIA EM SAÚDE (CIEVS). Boletim Semanal DCZ. Semana 4. Diretoria de Vigilância em Saúde. Prefeitura Municipal de Cuiabá. 2017.

INSTITUTO BRASILEIRO DE GEOGRAFIA E ESTATÍSTICA (IBGE). Cuiabá. Disponível em http://www.cidades.ibge.gov.br/v3/cidades/municipio/5103403 2016.

JUNQUEIRA, F.; ROCHA, M.C.; ABATI, P. Dengue e a chikungunya, doenças socioambientais. Disponível em http://www.cartaeducacao.com.br/aulas/doencas-socioambientais/ 2015.

MENDONÇA, F. (org.). S.A.U.- Sistema Ambiental Urbano: uma abordagem dos problemas socioambientais da cidade. p. 185-208. In: MENDONÇA, F. de A. (org.). Impactos Socioambientais Urbanos. Curitiba: Ed. da UFPR, 2004.

MENDONÇA, F.A.; SOUZA, A.V.; DUTRA, D.A. Saúde pública, urbanização e dengue no Brasil. Soc. nat. (Online), Uberlândia, v. 21, n. 3, p. 257-269, 2009.

NATAL, D. Bioecologia do Aedes aegypti. Biológico, São Paulo, v.64, n.2, p.205207, jul./dez., 2002.

OMS. Organização Mundial da Saúde. Dengue e dengue hemorrágica. Registro Epidemiológico Semanal. 75(24): 193-200, 2000.

PORTAL EBC. Primeiro caso de zika no Brasil completa um ano neste sábado (7). Disponível em http://www.ebc.com.br/noticias/saude/2016/05/primeiro-caso-de-zika-no-brasil-completa-um-ano-conheca-os-desafios-no 2016.

SANTOS, D.N.; AQUINO, E.M.L.; MENEZES, G.M.S.; PAIM, J.S.; SILVA, L.M.V.; SOUZA, L.E.P.F.; TEIXEIRA, M.G.; BARRETO, M.L. Documento de posição sobre a tríplice epidemia de Zika-Dengue-Chikungunya. Observatório de Análise Política em Saúde. 2016.

UJVARI, S. C. A história e suas epidemias: a convivência do homem com os microorganismos. 2a edição. Rio de Janeiro: Editora Senac Rio e Editora Senac São Paulo, 328p. 2003.

ZARA, A.L.S.A.; SANTOS, S.M.; FERNANDES-OLIVEIRA, E.S.; CARVALHO, R.G.; COELHO, G.E. Estratégias de controle do Aedes aegypti: uma revisão. Epidemiol. Serv. Saúde, Brasília, 25(2):391-404, abr-jun 2016. 